\title{
Design and Development of Triple Band Monopole Antenna and Effect of Slot on Notch Band Variation
}

\author{
M. Veereshappa ${ }^{1}$ and Dr.S.N Mulgi ${ }^{2}$ \\ Department of PG Studies and Research in Applied Electronics, Gulbarga University, Gulbarga 585 106, \\ Karnataka, India
}

\begin{abstract}
This paper presents the design and development of monopole antenna for triple band operation. The effect of slot is studied for varying the notch band operation of the antenna without changing the nature of ominidirectional radiation characteristics in its operating band. It is found that the antenna reduces the maximum notch band from $2.03 \mathrm{GHz}$ to $0.86 \mathrm{GHz}$ between the first two bands and 0.48 to $0.46 \mathrm{GHz}$ between second and third bands when width of the vertical slots are varied to $0.65 \mathrm{~cm}$. The antenna operates from $4.72 \mathrm{GHz}$ to $15.77 \mathrm{GHz}$. The proposed antenna is realized from conventional rectangular monopole microstip antenna using low cost FR4 epoxy. The antenna is simple in its geometry and easy to fabricate. Experimental results are in close agreement with the simulated results. The proposed antenna may find application in microwave communication systems.
\end{abstract}

Keywords: microstrip antenna, monopole, notch band, ominidirectional, slot

\section{INTRODUCTION}

Microstrip antennas have become the favourite choice of antenna designers because of their numerous advantages such as light weight, low profile, low volume, planar configuration, low cost, compatibility with integrated circuits and easy to fabricate [1-2]. These features make the antenna more useful for many microwave communication applications. Monopole antennas are designed with complex geometry to improve the notch band operation [3-4]. The antenna of complex geometry or bigger in size are of less practical applications. Circular, elliptical, triangular, square and rectangular are used to construct the monopole antennas [5-14]. In this paper a simple technique has been demonstrated to construct the monopole antenna which is realized from conventional rectangular microstrip antenna for triple band operation. By varying the width of two vertical slots placed on the patch the variation in the notch band is achieved without affecting the monopole characteristics of the antenna.

\section{DESIGN OF ANTENNA GEOMETRY}

The art work of the proposed antenna is sketched by using computer software Auto-CAD to achieve better accuracy and is fabricated on low cost FR4-epoxy substrate material of thickness of $\mathrm{h}=1.6 \mathrm{~mm}$ and permittivity $\varepsilon_{\mathrm{r}}=4.4$.

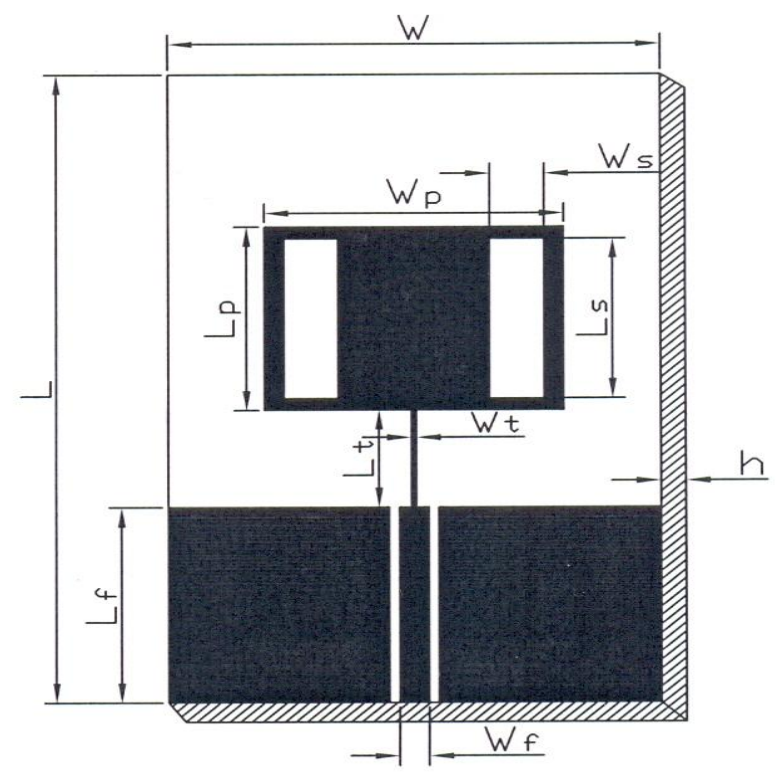

Fig. 1 Top view geometry of TMA 
IOSR Journal of Engineering

Apr. 2012, Vol. 2(4) pp: 650-655

Figure 1 shows the top view geometry of triple band monopole antenna (TMA). In this figure the antenna uses a substrate area of $\mathrm{L} \times \mathrm{W} \mathrm{cm}$. On the top surface of the substrate a ground plane of height which is equal to the length of microstripline feed $\mathrm{L}_{\mathrm{f}}$ is used on either sides of the microstripline with a gap of $1 \mathrm{~mm}$ between the ground plane and microstripline feed. On the bottom of the substrate a continuous ground copper layer of height $\mathrm{L}_{\mathrm{f}}$ is used below the microstripline. The TMA is designed for $3 \mathrm{GHz}$ using the equations available for the design of conventional rectangular microstrip antenna in the literature [2]. The length and width of the rectangular patch are $\mathrm{L}_{\mathrm{p}}$ and $\mathrm{W}_{\mathrm{p}}$ respectively. The feed arrangement consists of quarter wave transformer of length $\mathrm{L}_{t}$ and width $\mathrm{W}_{\mathrm{t}}$ which is connected as a matching network between the patch and the microstripline feed of length $\mathrm{L}_{\mathrm{f}}$ and width $\mathrm{W}_{\mathrm{f}}$. A semi miniature-A (SMA) connector is used at the tip of the microstripline feed for feeding the microwave power.

In Fig. 1 two vertical slots are placed on the patch having the length $L_{s}$ and width Ws for providing different surface current paths so as to produce multi resonant modes. The two slots are kept at a distance of $2 \mathrm{~mm}$ from the vertical and horizontal edges of the radiating patch. The design parameter of the proposed antenna is given in Table 1

Table 1

Designed parameters of proposed antenna

\begin{tabular}{|l|l|l|l|l|l|l|l|l|l|l|}
\hline $\begin{array}{l}\text { Antenna } \\
\text { parameter }\end{array}$ & $\mathrm{L}$ & $\mathrm{W}$ & $\mathrm{L}_{\mathrm{p}}$ & $\mathrm{W}_{\mathrm{p}}$ & $\mathrm{L}_{\mathrm{f}}$ & $\mathrm{W}_{\mathrm{f}}$ & $\mathrm{L}_{\mathrm{t}}$ & $\mathrm{W}_{\mathrm{t}}$ & $\mathrm{L}_{\mathrm{s}}$ & $\mathrm{W}_{\mathrm{s}}$ \\
\hline $\begin{array}{l}\text { Dimensions } \\
\text { in cm }\end{array}$ & 8.0 & 5.0 & 2.34 & 3.04 & 2.48 & 0.3 & 1.24 & 0.05 & 2.04 & 0.55 \\
\hline
\end{tabular}

\section{EXPERIMENTAL RESULTS}

The antenna bandwidth over return loss less than $-10 \mathrm{~dB}$ is simulated using HFSS simulating software and then tested experimentally on Vector Network Analyzer (Rohde \& Schwarz, Germany make ZVK model 1127.8651). The variation of return loss verses frequency of TMA when $\mathrm{W}_{\mathrm{s}}=0.55 \mathrm{~cm}$ is as shown in Fig. 2. From this graph the experimental bandwidth (BW) is calculated using the equation,

$$
\mathrm{BW}=\left[\frac{f_{2}-f_{1}}{f_{\mathrm{c}}}\right] \times 100 \%
$$

were, $f_{1}$ and $f_{2}$ are the lower and upper cut of frequencies of the band respectively when its return loss reaches $-10 \mathrm{~dB}$ and $f_{c}$ is the center frequency of the operating band. From this figure, it is found that the antenna operates between 4.74 to $15.91 \mathrm{GHz}$ and gives three resonant modes at $4.78 \mathrm{GHz}$ which is due to the fundamental resonant frequency of the patch and others modes at 8.94 and $14.01 \mathrm{GHz}$ are due to the novel geometry of TMA. The fundamental resonant mode frequency shifts from the designed frequency of $3 \mathrm{GHz}$ to $4.74 \mathrm{GHz}$ due to the coupling effect of

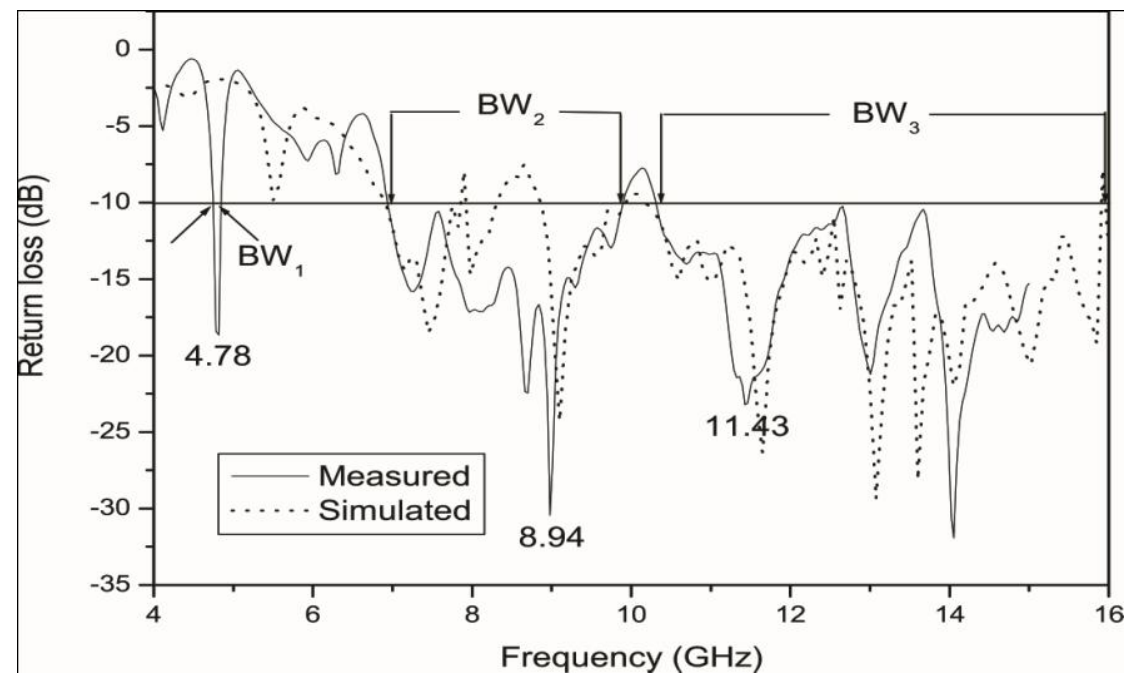

Fig. 2 Variation of return loss versus frequency of TMA when $\mathrm{W}_{\mathrm{s}}=0.55 \mathrm{~cm}$ 
IOSR Journal of Engineering

Apr. 2012, Vol. 2(4) pp: 650-655

microstripline feed and top ground plane of TMA. The magnitude of experimental -10 dB bandwidth measured for BW $\mathrm{BW}_{1}$ to $\mathrm{BW}_{3}$ are found to be $110 \mathrm{MHz}(2.29 \%), 2.98 \mathrm{GHz}(35.60 \%)$ and $5.57 \mathrm{GHz}(42.45 \%)$ respectively with a notch band from 4.85 to $6.88 \mathrm{GHz}$ between $\mathrm{BW}_{1}$ to $\mathrm{BW}_{2}$ and 9.86 to $10.34 \mathrm{GHz}$ between $\mathrm{BW}_{2}$ to $\mathrm{BW}_{3}$.

Fig. 3 shows the variation of return loss versus frequency of TMA when $\mathrm{W}_{\mathrm{s}}=0.65 \mathrm{~cm}$. From this figure it is clear that, the notch band is reduced from $2.03 \mathrm{GHz}$ to $0.86 \mathrm{GHz}$ between the first two bands i.e $\mathrm{BW}_{4}$ and $\mathrm{BW}_{5}$ and 0.48 to $0.46 \mathrm{GHz}$ between second and third bands i.e $\mathrm{BW}_{5}$ and $\mathrm{BW}_{6}$. The magnitudes of these operating bands measured at $\mathrm{BW}_{4}$ to $\mathrm{BW}_{6}$ are found to be 160 $\mathrm{MHz}(3.3 \%), 0.78 \mathrm{GHz}(12.72 \%)$ and $8.79 \mathrm{GHz}(77.27 \%)$ respectively. However the fundamental resonant mode $4.84 \mathrm{GHz}$ of $\mathrm{BW}_{4}$ remains almost near when compared to fundamental resonant mode $4.78 \mathrm{GHz}$ of $\mathrm{BW}_{1}$ as shown in Fig. 2 inspite of variation in the notch bands. The experimental and simulated results are in close agreement with each other.

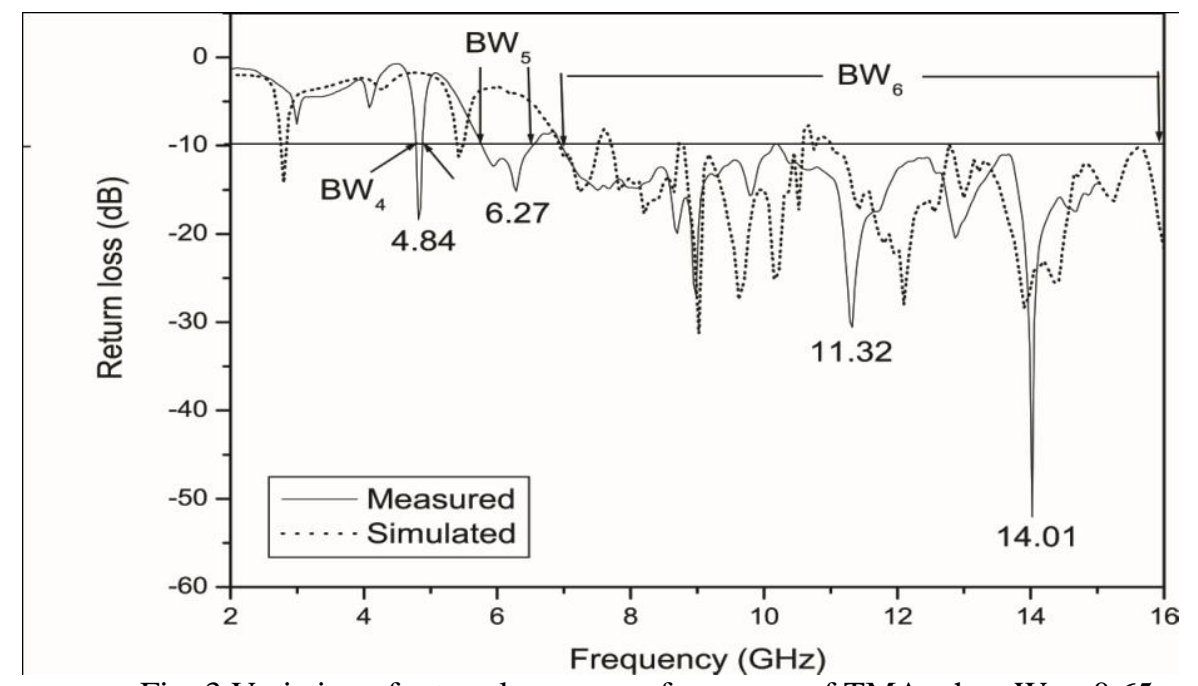

Fig. 3 Variation of return loss versus frequency of TMA when $\mathrm{W}_{\mathrm{s}}=0.65 \mathrm{~cm}$

The co-polar and cross-polar radiation pattern of TMA when $\mathrm{W}_{\mathrm{s}}=0.65 \mathrm{~cm}$ is measured in its operating bands. The typical radiation patterns of TMA measured at $4.84 \mathrm{GHz}, 6.27 \mathrm{GHz}$ and $11.32 \mathrm{GHz}$ are as shown in Fig 4, 5 and 6 respectively. The obtained patterns are ominidirectional in nature.

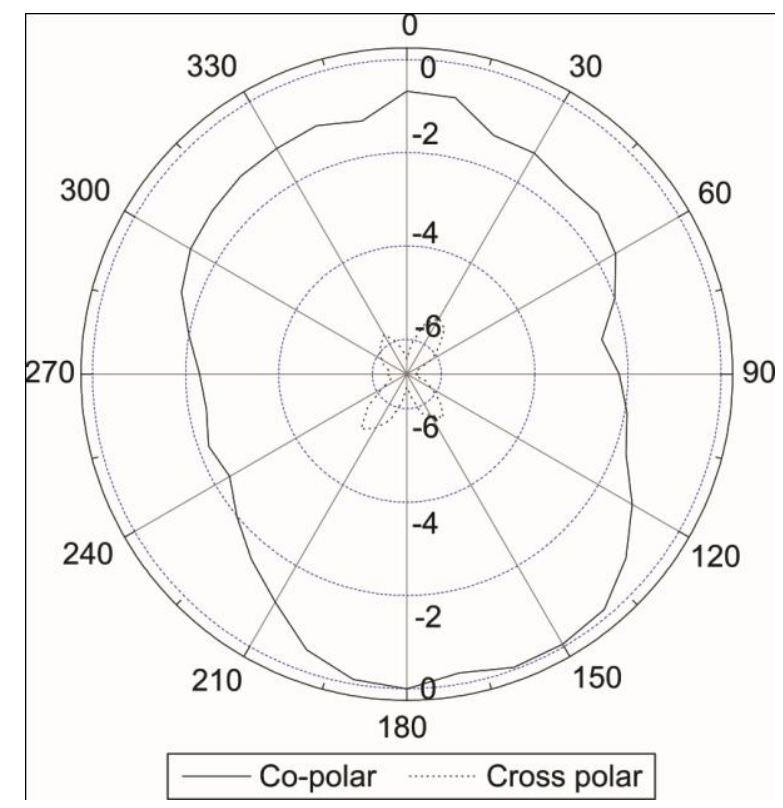

Fig. 4 Radiation pattern of TMA with $\mathrm{W}_{\mathrm{s}}=0.65 \mathrm{~cm}$ measured at $4.84 \mathrm{GHz}$ 
IOSR Journal of Engineering

Apr. 2012, Vol. 2(4) pp: 650-655

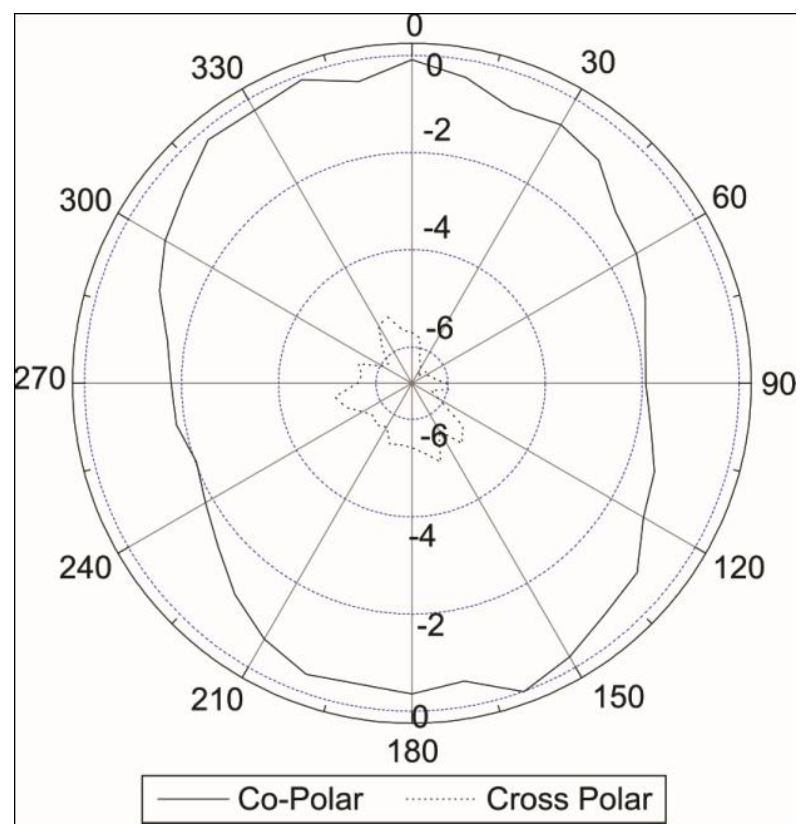

Fig. 5 Radiation pattern TMA with $\mathrm{W}_{\mathrm{s}}=0.65 \mathrm{~cm}$ measured at $6.27 \mathrm{GHz}$

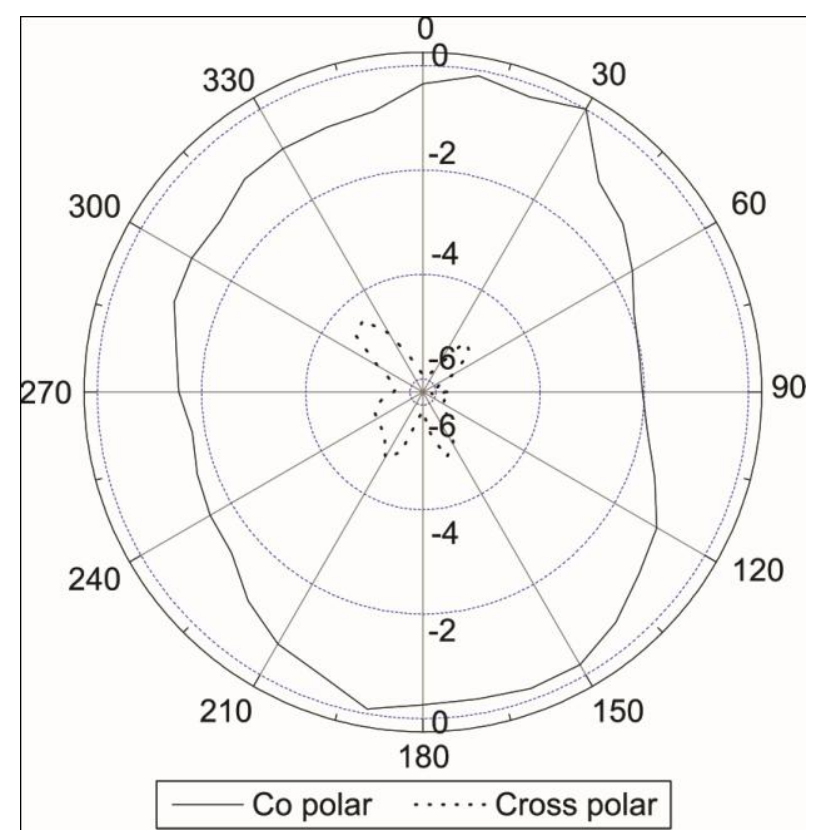

Fig. 6 Radiation pattern TMA with $\mathrm{W}_{\mathrm{s}}=0.65 \mathrm{~cm}$ measured at $11.32 \mathrm{GHz}$ 
IOSR Journal of Engineering

Apr. 2012, Vol. 2(4) pp: 650-655

The gain of the proposed antenna is measured by absolute gain method [1] using formula,

$$
\text { (G) } d B=10 \log \left(\frac{P_{r}}{P_{t}}\right)-\left(G_{t}\right) d B-20 \log \left(\frac{\lambda_{0}}{4 \pi R}\right) d B
$$

where, $P_{t}$ is the power transmitted by pyramidal horn antenna, $P_{r}$ the power received by antenna under test (AUT), $G_{t}$ the gain of the pyramidal horn antenna and R the distance between transmitting antenna and AUT. The experimental gain of TMA when $\mathrm{W}_{\mathrm{s}}=0.65 \mathrm{~cm}$ is measured across the operating bands. The variation of gain verses frequency of this antenna is as shown in Fig. 7. It is seen that maximum $20.58 \mathrm{~dB}$ gain is achieved at $4.84 \mathrm{GHz}$.

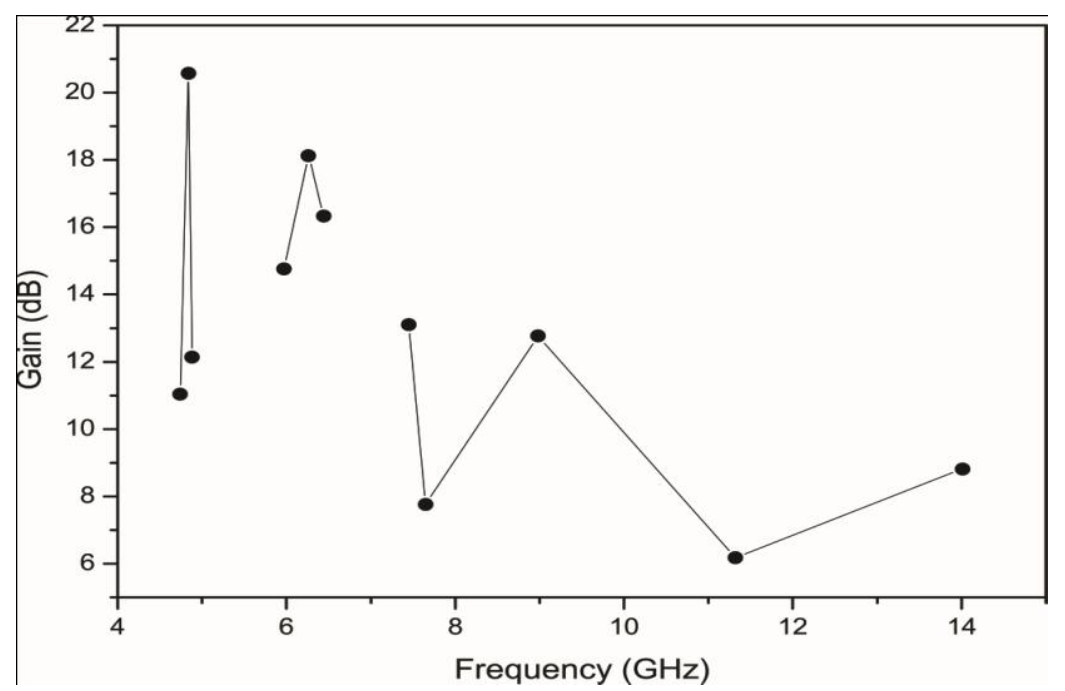

Fig. 7 Variation of gain versus frequency of TMA when $\mathrm{W}_{\mathrm{s}}=0.65 \mathrm{~cm}$

\section{CONCLUSION}

From the detailed experimental study, it is concluded that the TMA derived from conventional rectangular microstrip antenna is quite capable in producing triple band operation. The effect of two vertical slots placed on the patch is studied for varying the notch band operation of the antenna without changing the nature of ominidirectional radiation characteristics in its operating band. It is found that the antenna reduces the maximum notch band from $2.03 \mathrm{GHz}$ to $0.86 \mathrm{GHz}$ between the first two bands and 0.48 to $0.46 \mathrm{GHz}$ between second and third bands when width of the vertical slots are varied to $0.65 \mathrm{~cm}$. The antenna operates from $4.72 \mathrm{GHz}$ to $15.77 \mathrm{GHz}$. The antenna gives ominidirectional radiation characteristics in its operating band. The simulated and experimental return loss results of TMA are in close agreement with each other. The proposed antenna is simple in its design and fabrication. The antenna is constructed using low cost FR4 substrate material. This antenna may find any applications in microwave communication systems.

\section{ACKNOWLEDGEMENTS}

The authors would like to thank Dept. of Sc. \& Tech. (DST), Govt. of India. New Delhi, for sanctioning Vector Network Analyzer to this Department under FIST project. The authors also would like to thank the authorities of Aeronautical Development Establishment (ADE), DRDO Bangalore for providing their laboratory facility to make antenna measurements on Vector Network Analyzer. 
IOSR Journal of Engineering

Apr. 2012, Vol. 2(4) pp: 650-655

\section{REFERENCES}

1 Constantine A. Balanis, Antenna theory analysis and design, (John Wiley, New York, 1997).

2 I. J. Bahl and P. Bharatia, Microstrip antennas, (Dedham, MA: Artech House, New Delhi, 1981).

3 Shi-Wei Qu Jia- Lin Li and Quan Xue, A band notched ultra wide band printed monopole antenna, IEEE Antennas and Wireless Propag Lett, 5, 2006, $495-498$.

4 L.-H. Ye and Q. -X. Chu, Improved band-notched UWB slot antenna, Electron lett, 45(25), 2009.

5 C.C Liang. J. Chiau, Chem, and C. G. Parini, Printed circular disc monopole antenna for ultra wideband applications. Electron Lett, 40(20), 2004, 1246-1248.

6 C. Y Huang and W.C. Hsia, Planar elliptical antenna for ultra wideband application, Electron Lett, 41(6), 2005, 296 - 297.

7 C. C. Lin, Y. C. Kan, L. C. Kuo and H. R Chuang, A planar triangular monopole antenna for UWB communication, IEEE Microwave and Wireless components Lett, 15(10), 2005, 624-626.

8 K. P. Ray Y. Ranga and P. Gabhale, Printed square monopole antenna with semicircular base for ultra-wide bandwidth, Electron Lett, 43(5), 2007, 263-265.

9 M. John and M. J Ammann, Optimization of impedance bandwidth for the printed rectangular monopole antenna, Microwave Opt Technol Lett, 47(2), 2005, 153-154.

10 K. P. Ray and Y. Ranga, Printed rectangular monopole antenna, Proc. IEEE APS Int. Symp, New Mexico, USA, 2006, 1636-1639.

11 K. P. Ray and Y. Ranga, Ultra wideband printed modified triangular monopole antenna. Electron Lett, 42(19), 2006, 1081- 1082.

12 K. Song, Y. Z. Yin, S. T Fan, Y. Z Wang and L. Zhang, Open L-slot antenna with rotated rectangular patch for bandwidth enhancement, Electron Lett, 45(25), 2009, 1286 - 1288.

13 Jia- Yi Size, Kin-lu Wong, Slotted rectangular microstip antenna for bandwidth enhancement, IEEE Trans Antennas Propagat, 48, 2000, 1149-1152.

14 K. G. Thomas and M. Sreenivasan, Compact triple band antenna for WLAN, WiMAX applications, Electron lett, 45(16), 2009, 811-813. 